\title{
El tercer sueño de Echegaray (Psicoanálisis y literatura)
}

\author{
Echegaray's third Dream \\ (Psychoanalysis and literature)
}

Javier Fornieles

Universidad de Almería

Luis López Sánchez

Centro de salud mental Infante. Murcia

\section{RESUMEN}

En sus Recuerdos, Echegaray comenta tres pesadillas recurrentes. El estudio de estos sueños nos permite conocer las preocupaciones del escritor: los problemas y los conflictos originados por su trabajo como dramaturgo, así como la insatisfacción que experimenta por haber renunciado al estudio de las matemáticas, su verdadera vocación.

Palabras Clave: Echegaray, psicoanálisis, literatura.

\section{ABSTRACT}

In his Recuerdos, Echegaray writes three bad dreams. The analysis of these dreams let us know some of the writer's worries, such as problems and conflicts caused by his job as a playwright and, above all, the dissatisfaction he feels for having given up in part his real vocation: mathematics.

Key words: Echegaray, Psychoanalysis, Literature.

En la segunda mitad del siglo XIX la figura de José Echegaray muestra una especial complejidad. Ingeniero, economista, matemático, político, dramaturgo, su biografía destaca tanto por la diversidad de intereses e inquietudes como por la importancia de los galardones recibidos y las responsabilidades que desempeñó: ministro de Fomento y Hacienda en diversos periodos, presidente de la Real Academia de Ciencias Exactas, premio Nobel de literatura...

La variedad de sus actividades impresionó a sus coetáneos. Y, en cierto sentido, desconcierta hoy aún a quienes se aproximan a su obra y biografía por la dificultad para atender los perfiles tan contradictorios que ofrece. No parece fácil conciliar, por ejemplo, la recuperación del teatro romántico y el 
radicalismo de sus discursos en favor del individuo y de sus libertades, por un lado, con su estricto sentido de la disciplina, con su empeño en conseguir que cualquier actividad responda a una norma, a una ley precisa, o con las continuas declaraciones en las que manifiesta su amor por la ciencia y en especial por las matemáticas, por otro. El propio Echegaray es consciente de estas contradicciones y juega con ellas ante los lectores mostrando su sorpresa por ser en la vida real el más 'pacífico de los hombres' y en el teatro el más 'sanguinario'; por el revuelo que originan sus declaraciones e intervenciones en la vida pública, y por ser, al mismo tiempo, un hombre disciplinado, siempre dispuesto a respetar las reglas y a cumplir con sus obligaciones.

En estas páginas, abordaremos precisamente algunas de estas facetas tan dispares en apariencia y procuraremos captar ciertos aspectos de su personalidad a partir de un texto olvidado. Nos referimos a uno de los capítulos incluidos en las memorias que publicó, con el título de Recuerdos, en La España Moderna, entre 1894 y 1911. En una de las entregas, aparecida en junio de 1895, Echegaray describe una experiencia singular y de gran interés para nuestros propósitos: tres sueños que se repiten de forma insistente en determinados periodos de su vida ${ }^{1}$.

La pretensión de utilizar estos textos para explicar ciertos aspectos contradictorios de su biografía supone, sin duda, un empeño arriesgado. A las precauciones habituales que es preciso adoptar cuando formulamos hipótesis e intentamos reconstruir el pasado, hay que sumar otras cautelas. Por un lado, debemos ser conscientes de la dificultad que implica analizar los conflictos psíquicos; por otro, debemos recordar la distancia que nos separa en el tiempo y el riesgo que implica valorar correctamente el sentido de las emociones y de las experiencias vitales del escritor.

A favor contamos con una serie de factores. En primer lugar, disponemos de numerosos datos sobre las actuaciones de Echegaray en la vida pública y de una gran cantidad de observaciones entre las que destacan las recogidas por Echegaray sobre su propia vida en los tres tomos de los Recuerdos ${ }^{2}$.

En segundo lugar, nos sirven de ayuda la precisión y la riqueza de las indicaciones formuladas por Echegaray en torno a estos tres sueños. A ello debemos unir — sin perder de vista la doble deformación que nos muestra este material: la que se produce durante el sueño; y la que presenta el recuerdo a la hora de reproducirlo verbalmente-, las continuas declaraciones del escritor en sus memorias sobre la veracidad de sus afirmaciones: «he de atenerme a hechos que presencié, a palabras que oí, a actitudes que observé, y que

\footnotetext{
${ }^{1}$ La descripción de estos sueños puede leerse en Echegaray (1917: I, 95-105). Los tres tomos de Recuerdos no contienen todos los capítulos publicados por Echegaray en diversas revistas. Sobre las memorias de Echegaray, véase Fornieles Alcaraz (2002-2003).

${ }^{2}$ Sobre las diversas actividades de Echegaray véanse Sobejano (1978), Samper (1985), Hernández (1989), Fornieles Alcaraz (1989), Sánchez Ron (1990), Echegaray (2002).
} 
procuraré trasladar con fría exactitud»; «soy, pues, un testigo que, declara en forma escueta los hechos, y nada más que los hechos que presenció» (Echegaray, 1917: III, 302); «estos recuerdos de hoy no tendrán más que un mérito, pero éste lo tienen: una sinceridad absoluta» (Echegaray, 1917: I, 105).

Contamos, por último, con una circunstancia muy favorable: la adecuación entre el material aportado por Echegaray en sus memorias y el método desarrollado por el doctor Gállego Meré. La propuesta de Alejandro Gállego pretende lograr un tratamiento objetivo de la estructura psíquica y permite realizar un diagnóstico psicodinámico mediante el análisis vivencial de sueños y recuerdos infantiles. El material exigido para efectuar el análisis es el aporte de sueños significativos y de recuerdos de la infancia, el material que Echegaray proporciona precisamente en sus Recuerdos ${ }^{3}$.

Sin olvidar los problemas que el análisis de este tipo de textos implica, procuraremos aprovechar los materiales de los que disponemos y las correspondencias que es posible realizar entre las observaciones efectuadas por el psicoanálisis y los datos que nos proporcionan la historiografía y las obras de Echegaray. Para comenzar, estudiaremos, en concreto, el último de los sueños y dejaremos para otro momento el análisis de los anteriores y de las relaciones que muestran los tres en su conjunto.

\section{EL TERCER SUEÑO}

De acuerdo con las indicaciones de Echegaray nos hallamos ante un sueño completo, reiterado, que se ha producido «no hace mucho», cercano, por tanto, a la fecha de 1895 en la que se publica el texto.

Intentamos, en principio, recoger los aspectos principales de las vivencias y del contenido manifiesto, de las imágenes, que el sujeto recuerda. En el sueño —nos indica Echegaray - él es el protagonista y aparece como «hombre formal» y autor dramático, cuyas obras se representan ya en América y Europa, pero sin proporcionarle la debida recompensa económica.

El sueño parte de unos hechos ciertos: el éxito internacional del escritor y las dificultades para cobrar los derechos de autor generados por las obras representadas en el extranjero ${ }^{4}$. Sin embargo, este último factor, que desenca-

${ }^{3}$ De acuerdo con esta metodología, se celebró una sesión de trabajo para analizar los sueños relatados por Echegaray en la que intervinieron diversos especialistas del Centro de Salud Mental Infante (Murcia): J.M. Soria, J.A. Aznar, E. Carrasco, J. Palazón, J. González. Sobre el método seguido por Alejandro Gállego y los fundamentos teóricos de la técnica aplicada en este trabajo, véanse Gállego (1995), López, Palazón, Carrasco, Sánchez y González (1994), Salorio (1992), Lledó Sandoval (2009), Jiménez, Ramírez, Mingote y Rallo (1988), Louis (1979), Rallo Romero (1986). A la muerte de A. Gállego se editó un cedé con el título En memoria de Alejandro Gállego. Selección de artículos y conferencias.

${ }^{4}$ La obtención de los beneficios relacionados con la representación de sus obras en el extranjero no es un tema baladí para el dramaturgo. Al margen de sus comentarios en los Re- 
dena el contenido de la pesadilla, se resuelve favorablemente al comenzar el sueño: Echegaray recibe una nota de las embajadas en la que se le comunica que podrá cobrar todos los derechos atrasados. Tras acudir al banco, recoge en el sueño «una fortuna, cuatro o cinco millones de reales» en billetes, que a duras penas consigue guardar en los bolsillos del abrigo.

Las buenas noticias no acaban aquí. Nada más salir del banco «un caballero muy elegante, muy fino, y con acento italiano» le hace saber que la actriz Eleonora Duse - la más prestigiosa junto a Sara Bernhardt en la escena internacional- acaba de llegar a Madrid y le invita a la lectura de una de las obras escritas por el dramaturgo para preparar su representación. Animado por las novedades, Echegaray acompaña al caballero y entra en una casa. Deja el abrigo en un perchero y aguarda en un salón a la espera de ser recibido por la actriz. Pasado un tiempo, alertado por la tardanza, Echegaray busca en vano su abrigo con el dinero: la casa está vacía y todo ha desaparecido.

Echegaray reacciona, sale a la calle, pide auxilio, «sin sombrero y sin abrigo y dando gritos». Todo es inútil: deambula por las calles de un Madrid desierto como si todo el mundo hubiera desaparecido y fuera «cómplice del robo». Al final encuentra un agente, quien le conduce de nuevo a un espacio interior: un caserón viejo y sombrío, dónde al parecer habían trasladado el gobierno civil. Pero el resultado de sus esfuerzos es similar; sus expectativas se ven de nuevo defraudadas y la experiencia resulta no menos angustiosa:

Me vi corriendo por unos pasillos muy negros y muy estrechos, sin puertas ni ventanas a ninguna parte, y sin que nadie acudiese a mí por más que yo pedía justicia a voz en cuello. Aquello era otra trama, otra maquinación, otra infamia nunca vista.

Atrapado en los pasillos, en un espacio laberíntico, el sueño introduce nuevos personajes cada vez más extraños:

Vi venir hacia mí un bulto: tenía forma de persona y tamaño de persona también, pero no era persona; era un monigote muy grande de cristal de colores.

Pero era persona porque andaba y gesticulaba desordenadamente y se puso a bailar delante de mí.

La sensación de angustia por parte del sujeto no hace sino aumentar: «me puse a temblar; sentí mucho frío, y la pesadilla llegó a su periodo álgido». Al fin, poseído por «una especie de furor ciego», rompe con el bastón el muñeco en mil pedazos, pedazos que caen sobre el suelo de mármol.

cuerdos, la preocupación de Echegaray por ejercer sus derechos como autor está acreditada por su participación en las asociaciones de la época que defienden los derechos de los autores: preside la Asociación Lírico-dramática; participa en las reuniones y está en el consejo de honor de la Asociación de autores, compositores y Propietarios de Obras teatrales, organizada por Fiscowich; y sigue de cerca las actividades de la Sociedad de Autores dirigida por Sinesio Delgado, a quien defiende, por ejemplo, en 1902, de los ataques que recibe. 
La pesadilla sigue su curso. Corriendo, Echegaray procura salir del edificio pero sólo encuentra corredores, pasillos, encrucijadas repletas de «monigotes de cristal», que danzan burlones a su alrededor y que él destruye con su bastón. La situación se torna cada vez más penosa:

Los corredores cada vez más negros y más estrechos: el suelo cada vez más lleno de vidrios y cristales: los monigotes de cristal brotando de todos los rincones y encrucijadas y convirtiéndose en turbas sin fin que yo no me cansaba de hacer triza. Hasta que finalmente se produce el despertar, al que Echegaray llega envuelto en sensaciones muy desagradables: «rendido y con un sentimiento indefinible de horror, de rabia y de repugnancia».

\section{ANÁLISIS DE LOS CONTENIDOS MANIFIESTOS PRESENTES EN EL SUEÑO}

Como sabemos, un sueño es fruto de una transacción: extrae elementos de la realidad y los manipula, los deforma, de acuerdo con sus propias reglas. En este caso nos encontramos con circunstancias, con actividades económicas o laborales, que podemos reconocer en la realidad histórica y en la propia vida de Echegaray: la resonancia alcanzada por su teatro, la existencia de una importante actriz, la Duse; el éxito desde el punto de vista económico que supone la representación de sus obras en los escenarios españoles; o la preocupación por parte del dramaturgo por aumentar sus ingresos y por cobrar sus honorarios como muestra su participación en las primeras iniciativas realizadas por los escritores para agruparse y exigir legalmente sus derechos.

Junto a este tipo de elementos, hallamos una serie de imágenes visuales deformadas, cuyo sentido debemos interpretar. Para ello, trataremos, en principio, de aclarar cuáles son los sentimientos fundamentales que bullen en torno a las imágenes, al contenido onírico manifiesto. Entre estos sentimientos podemos destacar los siguientes:

— La angustia («la pesadilla se hizo dolorosísima y por todo extremo angustiosa»), un sentimiento que comparte con el resto de los sueños relatados.

— La sensación de estar perdido, la soledad, los espacios vacíos: «Madrid se había quedado tan desierto como la casa del timo», «¿a quién amenazaba si no había nadie?», «la casa estaba desierta y desamueblada».

- La impotencia: «me puse a correr por toda la casa llamando a voces a todo el mundo. ¡Trabajo inútil! ...»; «sin que nadie acudiese a mí por más que yo pedía justicia a voz en cuello». Es cierto que el sujeto se sobrepone ante adversidad: sale a la calle, pide auxilio, busca la autoridad, destruye los muñecos; pero sus iniciativas no logran un resultado satisfactorio, no conducen a nada.

— La impresión de que todos se confabulan en su contra: «todo el mundo cómplice del robo; el fruto de mi trabajo, el porvenir de mi fami- 
lia, estafado indignamente por una combinación diabólica de las cinco partes del mundo».

Se trata además de una decepción, que tiene el carácter de afrenta, de un engaño, especialmente doloroso. Se ha producido justo tras la satisfacción plena de sus deseos - el cobro de los derechos- y tras el encuentro con la autoridad, el agente que debería ayudarle. Y a la frustración se suma, además, la burla:

Otra infamia nunca vista, (...) o todo Madrid se había muerto; o todos en comunidad se habían marchado a la Pradera del Santo a repartirse alegremente los cinco millones de mis derechos teatrales; (...) ellos (los monigotes de cristal) a danzar delante de mí y a burlarse de mí con sus muecas de cristal rajado.

Un cierto sentimiento de culpa —es él quien se descuida- como muestran, en cierto modo, los reproches recogidos en los comentarios con los que acompaña el relato del sueño:

Y yo nada, como un idiota, sin recordar que llevaba cinco millones en los bolsillos del abrigo». «Yo me dejé engañar por mí mismo como el más inocente labriego; y sin la menor desconfianza seguí al italiano del sueño»; «aquella noche llevaba sin duda en mi cabeza, a un imbécil y a un tunante, y entre los dos me estaban haciendo pasar un mal rato.

\section{LA EXPERIENCIA COMO AUTOR Y POLÍTICO}

Ahora bien, ¿qué relaciones guardan esos sentimientos — de orfandad, de frustración, de burla- que aparecen en el sueño, con la experiencia y la actividad literaria de Echegaray? De entrada, no resultan fáciles de establecer. En las imágenes recordadas, los contenidos emocionales del sueño se vinculan con sus actividades en los escenarios. Y esto nos coloca ante una situación paradójica. El contenido latente, los sentimientos que brotan en el sueño, no encajan bien con la biografía del escritor. En apariencia, si algo caracteriza la trayectoria de Echegaray como dramaturgo, es el éxito. Logra unos ingresos económicos nada despreciables; su labor es reconocida por actores, empresarios o escritores como Clarín o Galdós, que recurren a él en busca de consejo. Y, por si quedara alguna duda, debemos recordar que Echegaray obtiene una notable proyección internacional, que desemboca finalmente en la concesión del premio Nobel.

Según sus propias declaraciones, los móviles que le impulsan, cumplidos ya los cuarenta y tras haber sido ministro en varios Gabinetes, a emprender su carrera como dramaturgo - aumentar sus ingresos y escapar de las luchas internas y de los permanentes sinsabores de la política- se han cumplido con creces. Por una parte, sus beneficios como autor constituyen la envidia de sus colegas. Por otra parte, el reconocimiento que obtiene su talento en la vida 
pública española compensa cualquier aspiración. A finales del XIX nada es comparable, en efecto, al triunfo logrado en el teatro: los aplausos del público y la salida al escenario en las noches de estreno, las manifestaciones con antorchas por la ciudad para acompañar al dramaturgo a su domicilio, la presencia continua en los medios de comunicación, el asombro que provoca su capacidad para escribir de temas tanto científicos como literarios...

Para explicar esta disociación entre la angustia del sueño y la biografía de Echegaray, debemos recurrir a otros datos más escondidos de su personalidad. En este sentido, la lectura de sus cartas, de algunas obras y pasajes de sus memorias nos permiten ver las grietas que surgen en torno a esta imagen de éxito continuo, que acompaña al dramaturgo.

Señalamos algunos de esos desajustes que acompañan la imagen pública del escritor:

- Frente al retrato del hombre que impone su voluntad en el teatro durante un cuarto de siglo, los sentimientos expuestos por Echegaray muestran una realidad mucho más compleja. En ocasiones se ve a sí mismo no como la persona que reina en los escenarios, sino como quien debe seguir dócilmente las rutinas del público, las impertinencias e imposiciones de los actores y los empresarios:

Yo escribo dramas para el público y de éstos unos agradan y otros no; escribo algunos para mí y esos no gustan nunca.

El público no siente y no aplaude más que tres cosas: chistes más o menos toscos, valentías más o menos heroicas, o situaciones de efecto.

¡Qué me importa a mí esto! — comenta a propósito de Comedia sin desenlace-, ¡ni qué ilusión tengo yo por esa tontería, que es mayor tontería desde que me obligaron a variar el final (Menéndez Onrubia y Ávila Arellano, 1987: 201, 197, 218).

- El éxito y los requerimientos de las empresas le obligan, además, a producir a un ritmo forzado; convierten su tarea en una pesada obligación: «Me pongo a trabajar todos los días, porque es preciso, porque le prometí a usted tres dramas y yo cumplo lo que prometo», le indica a María Guerrero en 1892. Y años después llega a escribir en sus memorias: «Jamás he sido libre; siempre he tenido que aprender o que escribir por obligación».

- A lo anterior debemos añadir que la literatura constituye también un campo de luchas despiadadas, y que la posición privilegiada de Echegaray genera la censura enconada de las nuevas generaciones: en parte, por motivos estéticos y, en parte, por encontrar en él un obstáculo que les cierra el camino a los escenarios. De hecho, en la propia revista en la que se publican los Recuerdos, algunos críticos añaden en estas fechas comentarios mortificantes y señalan, por ejemplo, que el teatro de Echegaray recibe el aplauso del vulgo y la censura del público 
cultivado. A finales de siglo, a pesar del éxito que corona su teatro y de los homenajes públicos, Echegaray conoce muy bien la animadversión y las críticas que su obra recibe. Y en sus declaraciones, insiste, por este motivo, en las servidumbres a que le obligan las empresas y en su deseo de incorporarse a las nuevas tendencias, más realistas, «encarnadas en personajes de carne y hueso, de los que todos conocemos y tratamos» 5 .

Como vemos, los sinsabores y las vivencias de frustración del sueño asociadas a la literatura no resultan tan extrañas ni están tan alejadas de la experiencia vital del dramaturgo. En sus Recuerdos encontramos suficientes testimonios que nos hablan de un malestar íntimo, de una continua insatisfacción que rodea su labor como autor y que explica el despego con que se califica a sí mismo como «un literato tardío» y «de ocasión», «toda vez que no eran éstas mis aficiones, ni la literatura formaba parte de mis estudios y de mi carrera de profesor e ingeniero» (Echegaray, 1917: II, 62).

Ese desajuste entre la valoración del propio Echegaray y la imagen que se proyecta en torno a su labor como dramaturgo, no es algo que surja sólo en este campo. La desazón por las contrapartidas que los escenarios le imponen, se extiende a otras parcelas de su biografía y nos puede arrojar nueva luz sobre el origen de este sentimiento.

Nos fijamos, por esta razón, en los comentarios sobre su trayectoria política. Nombrado ya ministro muy joven, en 1869 , senador vitalicio y ministro de nuevo en 1905, la carrera de Echegaray parece casi siempre marcada también en este terreno por el éxito.

Sorprenden, por ello, de nuevo sus opiniones peyorativas sobre la política en los que brota el mismo sentimiento que aparece en sus comentarios sobre el teatro. Lejos de la aureola que acompaña su rápido ascenso en la vida pública, las observaciones de Echegaray no pueden ser más despectivas:

«Un candidato que cruza el distrito a que aspira, me hace el efecto de un pordiosero que va de casa en casa pidiendo limosna»; «en fin, para mí lo imposible, lo más opuesto a mi carácter» (Echegaray, 1910a: 47-48). «Yo no he tomado nunca parte activa en la política sino en aquellos casos en que las circunstancias han sido más fuertes que mi voluntad» (Echegaray, 1910b: 38).

El paso por la política lo considera, incluso, el periodo de su vida «más difícil y más desagradable». Y, más adelante, cuando interrumpe por unos meses la redacción de sus memorias para ocupar en 1905, la cartera de Ha-

\footnotetext{
${ }^{5}$ Véanse, por ejemplo, los comentarios de Echegaray (1917: I, 216-17). Y las observaciones negativas de Morote (1904: 128-29), Fernández Villegas (1893) y Altamira (1902: 23), quien indica, a principios de siglo, que el teatro de Echegaray «ha ido perdiendo rápidamente su influencia».
} 
cienda, indica a sus lectores que han sido cuatro meses y medio de «pesadilla» (Echegaray, 1917: II, 257).

\section{LA VERDADERA VOCACIÓN DEL ESCRITOR}

Si la literatura o la política no satisfacen, a pesar del éxito, las expectativas íntimas de Echegaray, ¿cuáles son entonces los ejes, las actividades, con las que Echegaray se considera, en cambio, identificado en el momento de redactar sus memorias?

Por encima de cualquier tarea o vocación, hay una que concita sin ninguna duda el entusiasmo del escritor: la ciencia y, más concretamente, las matemáticas. Las declaraciones de Echegaray no pueden ser más rotundas:

Mi primera afición, la más intensa, la perdurable, ha sido siempre la que me llevaba y me lleva hoy mismo, al estudio de las matemáticas puras, y, por extensión de éstas, al de la Física Matemática (Echegaray, 1917: I, 401).

Las matemáticas son sin duda, para Echegaray, mucho más que una disciplina científica. Constituyen algo vital, un refugio frente a las experiencias negativas de cualquier índole: «La curación de todas mis tristezas, el remedio de todos mis aburrimientos, el centro de todas mis ilusiones intelectuales, por decirlo de este modo, ha sido siempre el estudio de las matemáticas» (ibid.: 370).

Las afirmaciones realizadas por Echegaray en este sentido son continuas. El inicio de sus memorias se abre con una frase en la que exalta el momento histórico en que «imperó en las ciencias del mundo inorgánico el método, firme y sólido como ninguno, de la observación y la experiencia». En sus Recuerdos juega con la idea de que en el futuro la moral pueda fijarse con cálculos matemáticos, la posibilidad de hallar para los problemas sociales «una solución única, científica, inquebrantable». Y justifica su interés por la economía política y su pertinaz defensa del librecambio en el hecho de que estas ideas poseían «un rigor casi matemático».

Las matemáticas, sus conocimientos técnicos como ingeniero, los éxitos logrados en este terreno en su juventud (número uno de su promoción durante toda la carrera en la selecta Escuela de Caminos, académico de Ciencias con apenas 34 años) se alzan como el único lugar en que Echegaray ve realizada su identidad. Y suponen algo más que un ideal recreado con palabras. Los últimos años de su vida nos muestran precisamente el repliegue del dramaturgo a lo que considera su verdadera vocación: las clases de doctorado en la Universidad, las reuniones con otros ingenieros, la preparación de varios tomos de Física matemática. Y de ello dan fe además sus últimas decisiones: la entrega de su biblioteca personal y de la medalla del Nobel a la Academia de Ciencias, donde aún se conserva.

La ciencia supone, pues, la seguridad, la certeza, lo indiscutible, y calma los anhelos de Echegaray. Desde esta perspectiva podemos entender mejor la 
zozobra que implican, en cambio, la literatura o la política. En ambos casos, se trata de actividades que pueden representar justo lo contrario, de tareas en las que el sujeto se ve envuelto en una red de intereses, en una estructura de dependencia imposible de controlar y de predecir.

De acuerdo con la experiencia referida por Echegaray, la escena y la política restringen la autonomía del individuo, fuerzan incluso actuaciones que bordean el ridículo, le colocan en una posición desairada —el ministro como un pordiosero ante sus electores, las recomendaciones y los enfrentamientos políticos, el autor que debe rehacer sus obras por los caprichos de los intérpretes-, y nada tienen que ver con el brillo exterior que acompaña tales actividades.

Lejos de ser el terreno sobre el que se basa su autoestima, la escena y los cargos en la vida pública se convierten así en una fuente permanente de conflictos sobre su identidad y aspiraciones, pues generan un claro desajuste entre la propia valoración de su persona y la imagen pública, siempre tornadiza y exagerada. Frente a los intereses y las disputas vanas de la literatura o la política, las matemáticas y el selecto grupo de quienes las dominan ofrecen, en cambio, un terreno seguro, una cierta garantía de ecuanimidad, que nada tienen que ver con el público: «una especie de tiburón para el que toda carne de autor es apetitosa cuando se siente hambriento» (ibid.: 389).

La personalidad de Echegaray aparece, pues, marcada por el cumplimiento riguroso de sus obligaciones profesionales, por la seguridad que le brindan las actividades científicas como estudiante, como profesor o investigador a la hora de conseguir unos objetivos, de mostrar su competencia y establecer una imagen pública impecable. Y justo en el lado opuesto se sitúan las intrigas de la política o del teatro, las presiones de esos otros ámbitos de actuación en los que también interviene. En este sentido una frase resulta reveladora para apreciar la idealización del pasado académico, la clara distinción que se abre paso en la mente de Echegaray, y para comprender la intensidad de la pesadilla y la angustia que afronta como autor:

Dos o tres veces al año me examino, y no ante profesores como aquellos — se refiere a la Escuela de Caminos en su juventud-, que de antemano me tenían reservada la nota de sobresaliente, sino ante el público y la crítica, que siempre disponen de un reprobado formidable y sin apelación posible, pues toda apelación se juzga vanidad o soberbia (Echegaray: 1917: I, 52).

\section{LA ESTAFA DEL «IALIANO»}

Volvamos de nuevo al sueño y tratemos de examinarlo de acuerdo con estos nuevos datos.

El punto de partida no puede ser más propicio. El sujeto es un autor reconocido incluso fuera de nuestras fronteras. Va a poder obtener una suma 
extraordinaria por sus representaciones. Y una de las actrices más reputadas internacionalmente, Eleanora Duse, se interesa por sus obras.

Se diría que Echegaray parece haber cumplido las aspiraciones que le llevan a la literatura. Por un lado, si en repetidas ocasiones indica que la literatura es en gran parte un medio de obtener dinero, de asegurar el porvenir, ese objetivo se realiza, al fin, con creces en el sueño.

Por otro lado, la mención de la Duse se corresponde probablemente con las inquietudes que rodean a Echegaray en esta etapa de su vida, y no resulta tan extraña, pues tiene cierto asiento en la realidad. En abril de 1890 la actriz estuvo en Madrid. En una entrevista concedida al diario El País («Una visita a la Duse», 1890) se indica que la actriz le manda sus saludos a Echegaray y que en Italia ha representado El gran Galeoto, aunque en la obra no hay realmente un papel de mujer adecuado para ella.

La aparición de la Duse en el sueño parece desarrollar esas muestras de cortesía lanzadas por la actriz. De este modo, a la fama que le proporcionan sus continuos éxitos en el teatro, se suma ahora en el sueño la posibilidad de acallar las censuras de quienes critican sus dramas por su falta de realismo. Precisamente, quien lo llama en el sueño es la abanderada del naturalismo, la actriz aclamada por los jóvenes porque incorpora a su repertorio a autores como Zola o Ibsen y da la espalda a los excesos interpretativos, los alardes y los efectismos de los cómicos, tan habituales en los actores que representan el teatro de Echegaray y por los que empieza a ser criticado.

Sin embargo, la situación inicial que se dibuja al inicio del sueño —riqueza, prestigio internacional, reconocimiento, incluso, por parte de la minoría que le censura - se esfuma bruscamente. No hay tal cita con la actriz y el dinero, al fin conseguido, ha sido robado. En ambos casos ha sido víctima de un engaño realizado por un compatriota de la actriz, un italiano que, a pesar de sus palabras y elegantes maneras, sólo persigue un objetivo: quitarle su dinero. Se trata de una sospecha que Echegaray proyecta, quizás, también sobre no pocos de quienes le censuran y ven probablemente con envidia sus ingresos.

Pero hay alguien más detrás del engaño. Si nos fijamos en los comentarios del propio Echegaray, podemos destacar su descuido a la hora de guardar el dinero conseguido y su lucidez a la hora de hacerse él mismo responsable de los contenidos del sueño:

Mi italiano - y bien puedo llamarle mío puesto que yo lo forjé-.

Yo me dejé engañar por mí mismo como el más inocente labriego.

¡El maldito italiano! Creación, sin duda, de uno de mis hemisferios cerebrales, que estaba preparándose para dar un soberano timo al otro hemisferio. La estafa de lo consciente por lo inconsciente: porque, según parece, yo había preparado, a espaldas de mí mismo, un lazo a la imbecilidad de mi ser.

Evidentemente, los comentarios de Echegaray muestran su capacidad de observación y no le falta razón al señalar las conexiones entre el pérfido italiano y él mismo. 
En ese sentido, la desaparición del dinero, esa «estafa de lo consciente por lo inconsciente», puede tener otra interpretación. El robo de sus honorarios ¿no representa ese otro engaño vital que Echegaray está dando a su propia vida, al postergar sus auténticas aficiones con la excusa del dinero o movido por el brillo de los escenarios o la política? Lo que ocurre en el sueño ¿no es un justo castigo que recibe por sus acciones, por abandonar la seguridad de la ciencia y adentrarse en un campo marcado por el capricho, por el azar y las luchas literarias?

Al fin y al cabo, lo sucedido en el sueño no deja de ser casi la consecuencia natural para quien 'conoce', en su fuero interno, la injusticia que se esconde tras las recompensas y la fama que el teatro proporciona con respecto a la ciencia:

Descubrir un teorema nuevo y fecundo, forjar una teoría que a nadie se le hubiera ocurrido..., éste es un placer supremo en el orden intelectual. (...)

Pero esta clase de trabajos requiere tiempo, descanso... un año, dos años, tres años, acaso una vida. (...)

En cambio, un drama se piensa en una noche y se escribe en quince días, y, suponiendo que salga mal, proporciona al autor unos cuantos miles de reales (Echegaray, 1917: II, 292).

A sabiendas de cuáles son sus 'verdaderas' preferencias, él mismo ha aceptado esa situación injusta. Prefiere la ciencia, pero ha buscado el dinero fácil y ha seguido el camino de la literatura.

Como justificaciones mencionará el fracaso que acompañó la publicación de sus primeros libros científicos o la necesidad de asegurarse el porvenir: «Si yo hubiera sido rico... me hubiera ido, y me iría hoy mismo, a un rincón, a leer libros de matemáticas (ibid.). Pero el engaño de que ha sido objeto en el sueño reestablece en cierto sentido el equilibrio, representa el castigo adecuado por la traición a sus propios ideales. Al fin y al cabo, el dinero o el prestigio que el interés de la Duse por su obra puede acrecentar, ¿qué son sino un espejismo con respecto a la reputación imperecedera de la ciencia?

Y hay, además, otro aspecto que sin duda es necesario valorar y sobre el que es preciso volver al analizar los otros sueños. El éxito alcanzado por Echegaray aparece a su vez como una injusticia frente a la experiencia vital que rememora del padre. Pese a su talento, éste último no logra nunca la debida recompensa, según nos indica Echegaray en sus memorias. El trabajo abnegado del padre, la superación de todo tipo de dificultades, el sacrificio por la familia para sustentarla y proporcionar una carrera mejor a sus hijos, no han tenido más consecuencias que la falta de reconocimiento y la escasez de dinero (Fornieles Alcaraz, 1989: 51-53). Y es aquí, probablemente, donde se encuentra una de las raíces que vertebra la conducta y la personalidad del dramaturgo. 


\section{EL ENGAÑO Y LA BURLA}

Al margen de la estafa urdida por el italiano y la pérdida del dinero, el sueño prosigue su curso por vericuetos cada vez más tenebrosos. Ciertamente, hay que destacar una faceta del carácter de Echegaray, la energía con que afronta la adversidad: la oportuna reacción para protestar, para pedir auxilio y buscar a un agente, a la autoridad. Pero es necesario señalar, al mismo tiempo, la decepción que acompaña estos intentos. Nadie le ayuda; el sujeto está solo incluso en una ciudad como Madrid; y surge, además, la sospecha de que los ausentes sean cómplices del engaño.

Por encima de la capacidad para buscar auxilio, en el sueño se impone, en efecto, la sensación de fragilidad: no hay nada seguro, ningún apoyo exterior. La reacción del sujeto sólo sirve para terminar perdido por las calles, en una postura desairada, «sin sombrero y sin abrigo y dando gritos» por un Madrid fantasmal.

En este punto, hay además otros detalles del relato sobre los que conviene reparar y que muestran el carácter especialmente penoso del sueño. El hecho de que la zozobra sea causada por un engaño, «un timo», «una estafa», y que ésta sea en parte una afrenta personal, no es algo que debamos pasar por alto. No sólo nos hallamos ante una situación 'objetiva': el robo de algo sustancial, «el fruto de mi trabajo, el porvenir de mi familia»; nos hallamos también ante algo especialmente doloroso, humillante, por la forma de producirse. El sujeto termina, al fin, impotente, inmerso en una contienda desproporcionada: «Todo el mundo cómplice del robo», «estafado indignamente por una combinación diabólica de las cinco partes del mundo». Y se ve sometido a una burla cruel e inesperada por parte de quienes menos cabe esperarlo: ese fino y educado italiano o el representante de la autoridad.

La importancia de este aspecto, de hallarnos ante una burla, se aprecia mejor cuando observamos que los Recuerdos están llenos de anécdotas que muestran la especial sensibilidad del escritor a incurrir en situaciones en las que pueda quedar desairado, en ridículo: la caída de su sombrero al hemiciclo de las Cortes; la vergüenza que le produce pedir ayuda a los guardias cuando alguien lo sigue por la calle y teme ser agredido; el recuerdo de un traje verde con adornos en su infancia; la angustia que le produce cualquier pequeño fallo (el haber olvidado poner la hora de la citación en uno de los escritos que envía para convocar una reunión como Secretario de la Escuela de Caminos, por ejemplo); o los temores y la escasa habilidad para pedir ayuda a los actores, cuando no es aún un autor reconocido, por miedo a ver desairados sus deseos...

Ciertamente, se trata de un sentimiento común, que es preciso valorar, en este caso, de acuerdo con los usos y las costumbres del XIX, mucho más rígidos al respecto. Pero de su importancia nos hablan, por un lado, que sea el 
propio Echegaray quien reconoce su exagerado temor al ridículo; y el hecho indiscutible, por otro, de que se trata de situaciones nimias, que han permanecido, no obstante, en la memoria muchos años después.

El tono del relato incluido en sus Recuerdos puede producir, en este sentido, una cierta confusión. Echegaray comenta con cierto desenfado su situación, el engaño que sufre, y recurre con frecuencia al humor, a la ironía sobre sí mismo, para explicar lo sucedido en el sueño:

Yo había preparado, a espaldas de mí mismo, un lazo a la imbecilidad de mi ser; ( ...) aquella noche llevaba sin duda en mi cabeza, a un imbécil y a un tunante, y entre los dos me estaban haciendo pasar un mal rato.

El contrapunto jocoso no debe hacernos olvidar, sin embargo, la intensidad de las emociones concitadas por el sueño: «un sentimiento indefinible de horror, de rabia y de repugnancia», «la pesadilla se hizo dolorosísima y por todo extremo angustiosa». Y no debe hacernos perder de vista la posibilidad de que el humor, la ironía sobre sí mismo, sea una manera de anticipar las reacciones del lector, esto es, una forma de mantener el control y de anular los comentarios burlones que pueden provocar las confidencias que refiere. Podríamos considerarlo un mecanismo semejante a los matices discursivos, al relativismo y consciencia del carácter subjetivo de cualquier afirmación, con que Echegaray plantea de entrada el relato de la pesadilla: «En esta última, ya era yo hombre formal, o por hombre formal me tenía. Ya era autor dramático, o autor dramático me llamaban».

\section{LOS MUÑECOS DE CRISTAL}

La última parte del sueño resulta, sin duda, la más compleja y en ella los elementos aparecen con un mayor grado de deformación. Perdido en los pasillos del Gobierno Civil, Echegaray observa cómo los monigotes de cristal acuden a su encuentro mientras él mismo, dominado por «una especie de furor ciego», los destroza sin cesar, e intenta escapar, entre «angustias y ansias más intensas», de un edificio que es «un laberinto sin salida».

¿Quiénes son estos muñecos de cristal, de vivos colores, semejantes a personas, que le salen al paso con sus muecas burlonas?

En primer lugar, para ensayar una respuesta, recordamos que el sueño constituye, quizás, una proyección de sus ansias fracasadas, un castigo por traicionar otros anhelos. El éxito en la escena le ha permitido obtener una recompensa económica y una fama extraordinaria, pero mucho más superficial e inestable que la que el sujeto vislumbra en otros ámbitos como los ocupados por la ciencia y las matemáticas.

En segundo lugar, conviene advertir una diferencia que se introduce ahora en la pesadilla. Los escenarios escogidos en la primera parte del sueño han 
sido espacios públicos - las oficinas del banco, la casa en la que supuestamente le esperaba la Duse, el Madrid fantasmal - para llegar, finalmente, «al supuesto gobierno civil». Los comentarios sobre este último sitio, en los que el sueño se torna más complejo, o la ausencia de descripciones sobre este nuevo lugar, para ser más exactos, pueden resultar significativos. De él sabemos que es «un caserón viejo y sombrío». No hay ningún detalle preciso sobre el nuevo espacio: "no recuerdo el portal, no recuerdo la escalera, ni recuerdo el vestíbulo, ni sé como me vi dentro del caserón». No hay muebles, no hay estancias. Lo único que permanece en la memoria es el hecho de estar corriendo con un bastón en la mano, dando gritos, «por unos pasillos muy negros y muy estrechos, sin puertas ni ventanas a ninguna parte»; y la soledad que acompaña su petición de justicia, hasta el punto de plantearse determinadas cuestiones: «pero ¿a quién amenazaba — se pregunta— si no había nadie?», salvo él mismo.

Entramos así ahora en unos terrenos aún más resbaladizos. Ese caserón viejo y sombrío ¿se trata de una proyección del propio Echegaray, quién ha cumplido ya los sesenta y atraviesa, a principios de los noventa, un cierto periodo de decepción por la suerte de sus obras y las imposiciones a que se ve sometido por parte de actores y empresarios?

Ese espacio laberíntico, poblado «por unos pasillos muy negros y muy estrechos, sin puertas ni ventanas a ninguna parte», por los que nadie deambula salvo el propio sujeto, ¿podría señalar la propia mente del escritor/ soñante?

Y en ese caso, ¿qué representa la nueva proyección?, ¿qué significado tienen los muñecos? ¿Cuál es la relación que guardan con el núcleo del sueño: el sentido de culpa, la soledad, la decepción íntima, originada por la falta de autenticidad de la literatura como opción vital?

Fijémonos en sus características: los monigotes parecen casi personas, tienen la forma y el tamaño de una persona, pero son de colores, frágiles, desenfadados, y brotan sin cesar de los pasillos.

Esas criaturas descaradas, brillantes, ¿podrían ser los personajes de sus obras? Una serie de coincidencias apuntan en esta dirección. Los muñecos aparecen sin cesar en los pasillos laberínticos — ¿la mente del escritor?-; y proliferan tanto como las propias obras de Echegaray, quien trabaja sin descanso para cumplir sus compromisos y abastece el teatro nacional con dos o tres estrenos cada año, algo que le recriminan ya sus adversarios. Esos atrevidos muñecos de colores son llamativos — al igual que las ficticias criaturas que reciben el aplauso del público—, pero resultan tremendamente frágiles. Evocan sólo una apariencia de vida; al igual que los personajes en los escenarios no son seres reales, personas de carne y hueso. Y son, además, tan 'falsos', en parte, como la propia vida del autor, quien siente, a estas alturas de su vida, que ha traicionado, en cierto modo, su verdadera vocación.

Los monigotes de cristal se ríen, quizás, con motivo de quien los amenaza enfurecido con el bastón. A decir verdad, tienen múltiples razones para 
danzar, para gesticular desordenadamente y burlarse con sus muecas del propio Echegaray: conocen bien la 'fragilidad' de su fama, la distancia que existe entre la valoración inicial del sueño («ya era yo hombre formal, o por hombre formal me tenía») y la que el escritor anhela o considera más auténtica. Saben el justo castigo que el sujeto recibe en el sueño por prestarse al engaño, por perseguir el dinero y una fama efímera. Y conocen bien la imposibilidad de hacerles frente, pues ellos tienen, al fin y al cabo, el mismo origen que la mano que intenta en vano destruirlos.

\section{CONCLUSIÓN}

El relato de este sueño nos sitúa, pues, ante algunos de los ejes fundamentales de la personalidad de Echegaray. Nos referimos a la necesidad imperiosa de hallar un orden, un lugar seguro en el que la existencia pueda discurrir al margen del azar y las falsas valoraciones, aspectos que podemos encontrar también en sus obras de teatro, cuyos protagonistas se ven perseguidos con frecuencia por una serie de funestas casualidades o acosados por las intrigas o la maledicencia anónima.

Al mismo tiempo, el sueño recoge alguna de las íntimas contradicciones del escritor: la sensación de que su labor en los escenarios para obtener un mayor reconocimiento social y una posición económica desahogada, se ha llevado a cabo renunciando a lo que valora como sus auténticos deseos e ideales. Para el escritor, el éxito logrado se ha conseguido, en parte, sacrificando su dedicación al estudio de la física y las matemáticas, esto es, la posibilidad de conseguir una reputación mucho más sólida, fuera de los vaivenes y caprichos que rodean a la política o a la literatura. De ahí arrancarían los núcleos básicos de su sueño: los sentimientos de soledad, de estar siendo engañado por él mismo o de culpa por lo que le ocurre. Y de ahí surgiría el repliegue durante sus últimos años a las tareas académicas y científicas en las que Echegaray encontraba probablemente la seguridad y el equilibrio anhelados.

De este modo, el relato pormenorizado de un sueño y el análisis del mismo, de sus símbolos y desplazamientos, a partir de los datos históricos y de las técnicas empleadas por el psicoanálisis, nos permiten comprender algunos datos en apariencia contradictorios de la personalidad de Echegaray y nos muestran de nuevo la complejidad de los procesos que se dan cita en torno a la creación literaria. 


\section{BIBLIOGRAFÍA CITADA}

Altamira, Rafael (1902). «La literatura durante la Regencia», Nuestro Tiempo. II, pp. 19-32.

Echegaray, José (1910 a). «Recuerdos», La España Moderna. 262, pp. 47-53.

Echegaray, José (1910 b). «Recuerdos», La España Moderna. 263, pp. 35-44.

Echegaray, José (1917). Recuerdos. I-III. Madrid: Ruiz Hermanos editores.

Echegaray, José (2002). El gran Galeoto, ed. Javier Fornieles. Madrid: Castalia.

Fernández Villegas, Francisco (1893). «Impresiones literarias». La España Moderna. 52, pp. 202-207.

Fornieles Alcaraz, Javier (1989). Trayectoria de un intelectual de la Restauración: José Echegaray. Almería: Caja de Ahorros.

Fornieles Alcaraz, Javier (2001-2003). «Los Recuerdos de José Echegaray», Siglo Diecinueve. 8-9, pp. 177-226.

Gállego, Alejandro (1995). «Estudio dinámico del delirio y de la estructura psicótica de la personalidad», Revista de Psicoanálisis y Psicoterapia. 2, pp. 69-108.

Hernández, Librada (1989). El teatro de José Echegaray: un enigma crítico. UMI, Ann Arbor

López, L., Palazón, J., Carrasco, E., Sánchez, M.L. y González, J. (1994). «Análisis del contenido manifiesto de los sueños y los recuerdos infantiles como instrumento de exploración en las estructuras psicóticas», Revista de Psicoanálisis y Psicoterapia Analítica. I, pp. 84-108.

Louis, Victor (1979). «La interpretación de los sueños y primeros recuerdos de la infancia en la psicología de Adler», en Raymond Battegay y Arthur Trenkel (eds.), Los sueños: según las diversas escuelas psicoterapéuticas. Barcelona: Herder, pp. 27-53.

Lledó Sandoval, J.L (2009). La exploración psicodinámica en Salud Mental. Alicante: ECU.

Jiménez, M.A. Ramírez, F. Mingote, C. y Rallo, J. (1988). «Metodología del estudio del contenido manifiesto de los sueños», RAEN. VIII, 25, pp. 267-280.

Samper, Edgar (1985). José Echegaray. L'homme de science et le politicien en son temps. Recherches sur le libéralisme espagnol de 1860 à 1874 (Thèse). Nice: Université de Nice.

Menéndez Onrubia, Carmen y Ávila Arellano, Julián (1987). El neorromanticismo español y su época. Epistolario de José Echegaray a María Guerrero. Madrid: CSIC.

Morote, Luis (1904). Pulsos de España (interviews políticas publicadas Heraldo de Madrid y El Mundo de la Habana). Madrid: Estab. tip. de Ricardo Fé.

Rallo Romero, José (1986). «El doble contenido latente del sueño», Revista de Psicoanálisis de Madrid. 4, pp. 49-62

Sánchez Ron, José Manuel (1990). José Echegaray: matemático y físico-matemático. Madrid: Fundación Banco Exterior.

Salorio, P. (1992). «Valoración de la personalidad mediante el análisis de sueños y recuerdos infantiles en pacientes con anorexia nerviosa, neurosis y controles normales», Anales de Psiquiatria. VIII, n. ${ }^{\circ}$ 9, pp. 349-357.

Sobejano, Gonzalo (1978). «Echegaray, Galdós y el melodrama», Anales Galdosianos (Anejo), pp. 94-115.

«Una visita a la Duse», El País, 24.4.1890, p. 2.

Fecha de recepción: 21 de abril de 2010

Fecha de aceptación: 2 de diciembre de 2011 